\title{
AN APPROACH TO FIND LOCALIZATION OF NON-EXISTENT HISTORICAL BUILDINGS BY TERRESTRIAL PHOTOGRAMMETRY
}

\author{
U. Acar ${ }^{\mathrm{a}}$, B. Bayram ${ }^{\mathrm{a}}$,H.I. Cetin ${ }^{\mathrm{a}}$ \\ ${ }^{a}$ YTU, Civil Engineering Faculty, 34220 Esenler Istanbul, Turkey - (uacar, bayram, icetin)@ yildiz.edu.tr
}

CIPA, ICOMOS and WG V/2

KEY WORDS: Cultural Heritage, Rectification, Satellite Image, Photography, Transformation

\begin{abstract}
:
Preservation of cultural and historical values located in Bosphorus Area in Turkey and protection of natural structure is guaranteed by Bosphorus Law. According to the law, land owners who want to raise a new building in Bosphorus area can only do exactly like the previously constructed building in that area. In the event that there is no construction whatsoever regarding the building in the area, information about the building that will be constructed can only be reached by historical photographs.

The study that is presented is made with the purpose of identifying if the historical building that can only be reached by historical maps and photographs and is planned to be reconstructed in the Bosphorus area, is the building shown in photographs or not, and also if it is on the alleged area. Aerial photograph of 1937, actual 1/1000 scaled digital photogrammetric map and satellite image of the same area, historical perspective photograph that was taken between 1903-1907, actual photograph that was taken with around the same perspective and 3D Google Earth image which provides the same perspective are used for this process.

Historical buildings that remain the same until today are confirmed by the historical aerial photograph which includes study area and these buildings are used as control point. In the same way, with the historical perspective photograph, buildings that reach until today are confirmed and used as control point.

With the acquired results, that the building is totally in the alleged parcel is crosschecked with all methods and confirmed with the error of 1.8357 meters.
\end{abstract}

\section{INTRODUCTION}

According to the "2960. Bosphorus Law" which came into force in 1983 in Turkey, was defined the Bosphorus Region. According to the law, the permission for construction, the buildings, which are going to build in the region, have to be exactly the same as historical value of buildings. However, In order to rebuild the historical buildings that entirely collapsed needs to verify that the buildings were there before. For this problem, historical aerial photos, Bosphorus landscape photos which have been taken in the past, and historical depiction of the architectural buildings are obligatory information recourses and only the can be used.

The importance of cultural heritage for cultural, national, local or even individual identity is widely acknowledged in the literature (Aldridge, 1989; Uzzell, 1989; Hewison, 1989; Yilmaz et al., 2007). Photogrammetric modelling of buildings having great cultural value is becoming a common task during the last years (Balodimos,. et.al., 2003) and the Photogrammetry provides to define the characteristics of the objects and reconstruction of the objects without contact. Architectural and archaeological photogrammetry as a branch of close range photogrammetry has been developing rapidly since 1960s. Plans for historic buildings usually are achieved with this technique. Photogrammetry is more economical and reliable than classical methods. So, photogrammetry has an important role for protection of historical heritage (Aydar, et al., 2007)(Kirchhoefer, 2011).

Such as all the photogrammetry techniques, methodology in the close range photogrammetry has been started to use computer technology, too. So, in the close range photogrammetry has been used three dimensional visualization possibilities with the progress of computer technology (Pop, 2008).

Among the centuries, photogrammetry was applied with the photos that were taken by metric cameras. Nevertheless today, photogrammetry specialists evaluate the photos about the architectural objects with the scanning of the analog films or digital cameras by using non-metric cameras. Digital Image processing techniques has been started to use instead of analog systems, therefore, non-metric and half-metric cameras systems have been used. The advantages of their low prices and high resolution, the digital cameras have been utilized by the wide range of society (Pop, 2008), (M. Shashi, 2007), (Wei, 2012).

In this study, Aerial photograph of 1937, actual 1/1000 scaled digital photogrammetric map, satellite image of the same area and historical perspective photograph that was taken 1903-1907 have been determined the current location of the collapsed building.

\section{STUDY AREA}

This study has been enclosed in the city of İstanbul, Üsküdar, 124 sections, 684. Block and 9. Parcel in Turkey

Uskudar is located in the heart of the Bosphorus on the Asian side. There are a lot of places to see in and around it. Symbol of Uskudar, Maiden's Tower built on rocks out in the sea is surely among the places to be seen. There are mosques, churches and synagogues in this area. Famous mosques include Mihrimah Sultan Mosque designed by Mimar Sinan for Mihrimah Sultan, 
the favorite daughter of Sultan Suleyman the Magnificent and Semsi Pasha Mosque. There are close to 200 mosques in Uskudar, a few of them by famous Ottoman architect Mimar Sinan. In addition, many historical fountains are worth seeing, such as Fountain of Ahmed III with classical Ottoman style and Fountain of Huseyin Avni Pasha with Baroque style. There are also historical residences in greater Uskudar area such as Beylerbeyi Palace a 10 minute drive to the the north, Abdulaziz Hunting Villa and Adile Sultan Pavilion and madrasahs such as Ahmediye Madrasah and Mihrimah Sultan Madrasah (http://www.twarp.com/istanbul/uskudar.htm, 16 April 2012)

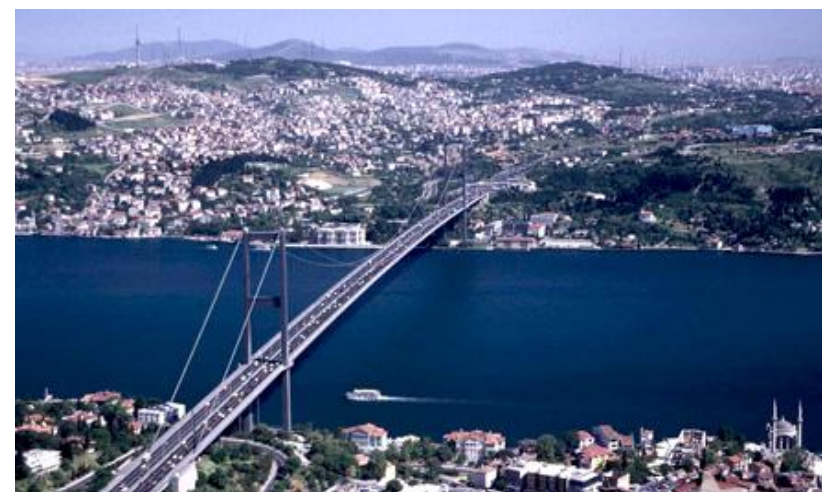

Figure 1. Üsküdar from the Europa side of Istanbul (http://www.garantitatil.com/istanbul-turu.html, 16 April 2012)

\section{METODOLOGY}

\subsection{Determination of the building by using Aerial Photo}

In order to determine the current location of the building, four 1:1000 scaled digital photogrammetric up to date maps have been used. The aerial photograph of building has been registered to the digital map by using projective transformation. The reason of using projective transformation is deviations from the central projection caused by lens distortion (http://encyclopedia2.thefreedictionary.com/Photogrammetry, 16 April 2012).

A photograph is an image made by projecting each point of an object on film plain (or sensor, which is the equivalent of film for digital cameras) in direction of lines through camera's lens optical centre (Stojaković, 2008).

With the both of map planes and photo planes conjugate control points transformation have been occurred. The mathematical model of the projective transformation is given in the following formula;

$$
\begin{aligned}
& X=\frac{a_{1} x+a_{2} y+a 3}{c_{1} x+c_{2} y+1} \\
& Y=\frac{b_{1} x+b_{2} y+b_{3}}{c_{1} x+c_{2} y+1}
\end{aligned}
$$

(Bayram, 2005)

In this study, to apply protective transformation on the aerial photograph, the ground control points were taken from digital photogrammetric maps. The projective transformation was resulted with the buildings which have still survived by using 30 ground control points. The results of the transformation are given in table 1 .

\begin{tabular}{|l|l|}
\hline Number of Points & 30 (none withheld) \\
\hline Degrees of Freedom & 52 \\
\hline Average Error & $1,8 \mathrm{~m}$ \\
\hline Point with Highest SSE & 5 \\
\hline Model & Projective \\
\hline
\end{tabular}

Table 1. Errors for projective transformation

The distribution of control points in the aerial photograph is given in the figure 2, and in the digital maps is given in the figure 3 . The average error of the transformation is calculated $1.8 \mathrm{~m}$. The printed analogue aerial photograph was scanned with 800 dpi.

Because of the unknown parameters of the aerial photograph, such as film features, photo scale, internal orientation parameters, the transformation error approximately 2 meters. Due to the using single aerial photographs the relief displacement errors also decreased the accuracy of transformation result. However, this result was enough accurate to determine the localization of the searched building. The result is presented in figure 4 with red circle. The length and width of the building were measured and presented also in figure 4 .

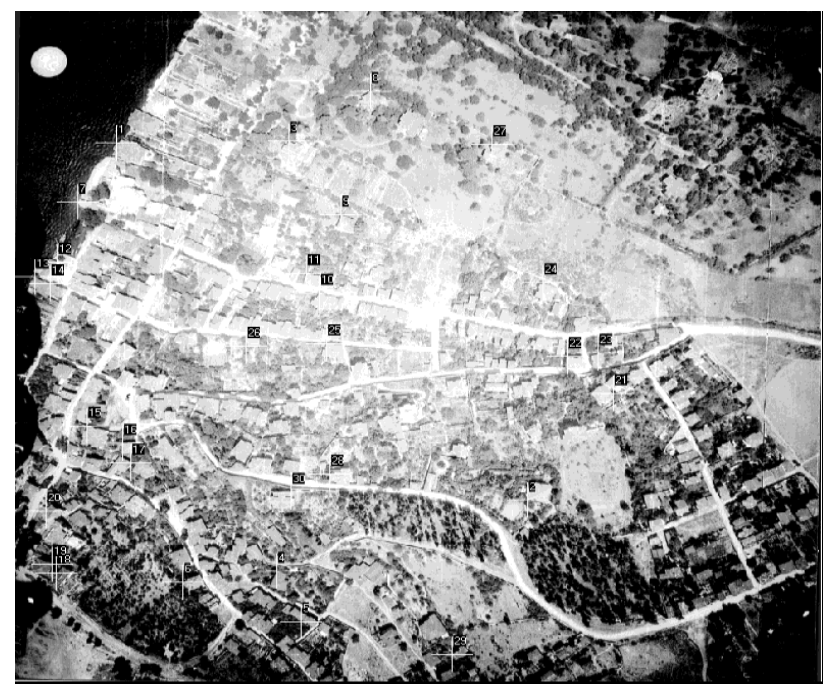

Figure 2. The distribution of the control points in the aerial photo

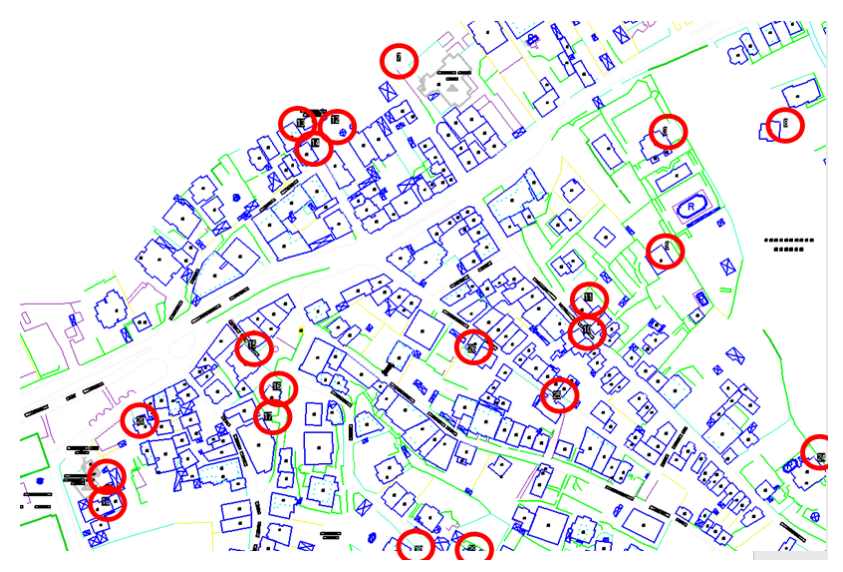

Figure 3. The distribution of the control points in the 1:1000 scaled digital map 


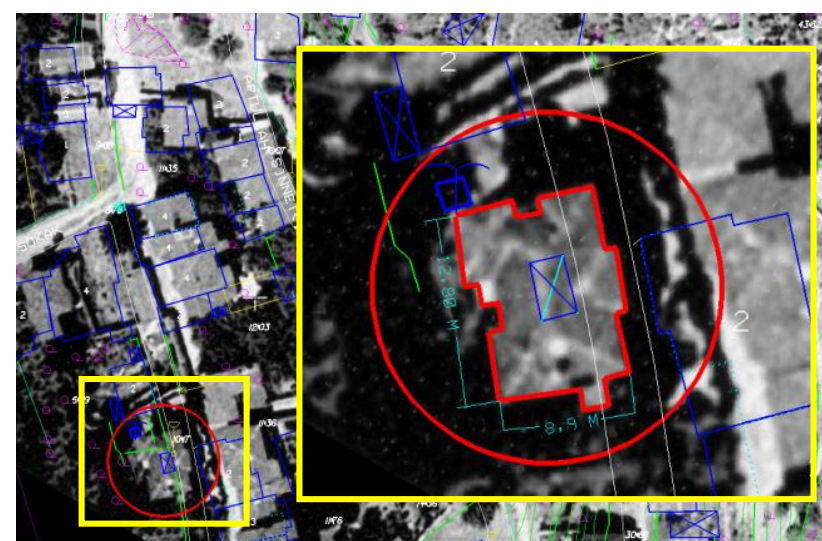

Figure 4. The location of building after the registration of the aerial photograph and digital map and the dimensions of building after the registration of the aerial photograph and digital map

\subsection{Determination of the Building by Using Historical and Up To Date Terrestrial Photographs}

After determining the localization of the building by using aerial photographs, historical and actual terrestrial photographs were used. The aim of this method was comparison of both photographs and to determine the localization of the historical building in actual photograph. It is only possible with the projective transformation. The projective relationship between two planes is at least probable with 4 conjugate control points (Tsioukas , 2007, Samuhelová, 2004).

The projective transformation was applied between historical photograph (figure 5) and actual photograph (figure 6). The actual photograph has been taken by Canon PowerShotG9. The specifications of the camera are given in table 2.

\begin{tabular}{|c|c|}
\hline Model & $\begin{array}{c}\text { Canon } \\
\text { PowerShotG9 }\end{array}$ \\
\hline Resolution & $4000 \times 3000$ \\
\hline Shutter Speed & $1 / 640 \mathrm{Sec}$. \\
\hline Lens & $\mathrm{f} / 4$ \\
\hline ISO & 80 \\
\hline Focal Length & $7 \mathrm{~mm}$ \\
\hline Date of Capture & 16.03 .2009 \\
\hline
\end{tabular}

Table 2. Specification of digital camera

Five control points were measured in the historical photograph and the actual photo. In order to find five control points, field work was done. The transformation results are given in table 3 . As seen in table 3, the historical building was in the related parcel in the registered photo. Also the region of the building depicted with the red circle in the actual photograph (figure 5, $6)$

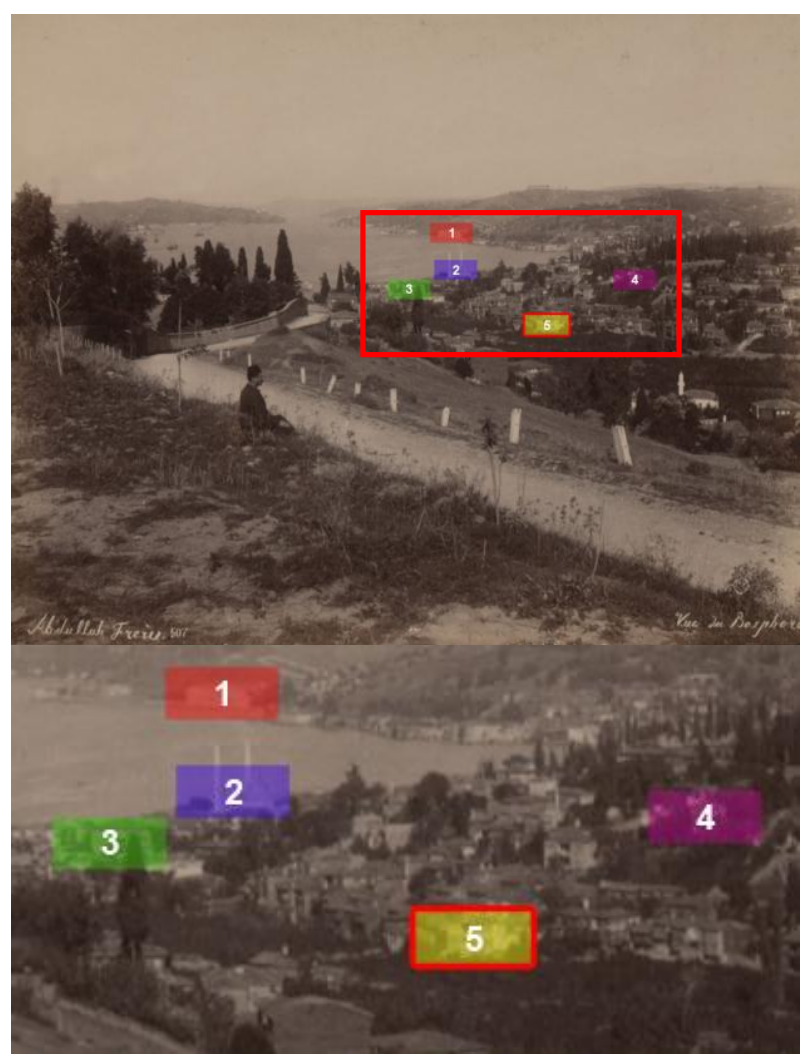

Figure 5. The historical photograph and control points

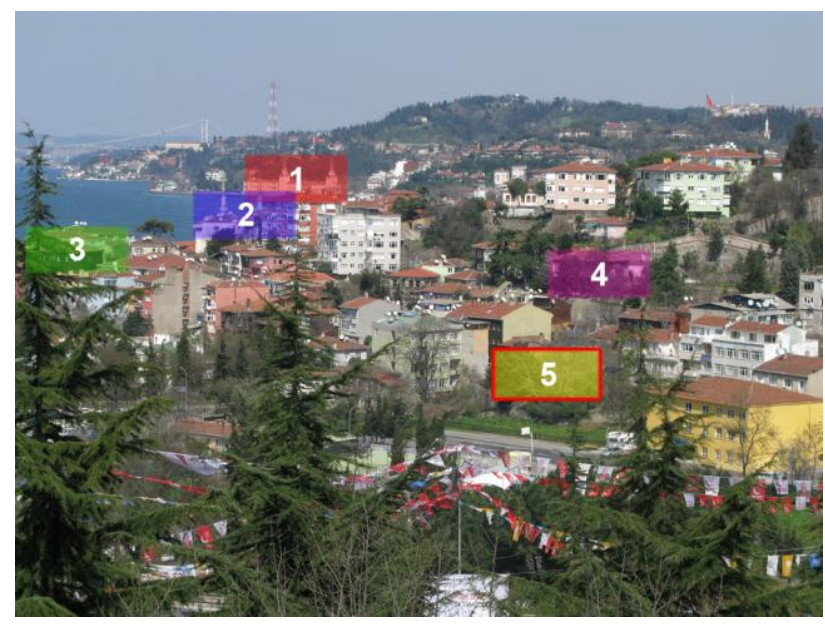

Figure 6 . The actual photograph and control points

\begin{tabular}{|l|l|}
\hline Number of Points & 5 (none withheld) \\
\hline Degrees of Freedom & 2 \\
\hline Average Error & 6.7 pixels \\
\hline Point with Highest SSE & 2 \\
\hline Model & Projective \\
\hline
\end{tabular}

Table 3. Errors of projective transformation

The standard error of the transformation was greater than one pixel. The reasons are as follows:

1. The undefined deformations of the historical photograph

2. Unknown interior orientation parameters 
3. Relief displacement errors due to using mono photographs.

After transformation, the locations of the buildings on the actual photographs and historical photographs were digitized and placed at 1:1000 scale digital photogrammetric maps. Thus, it has been seen that the location of the historical building is in the related parcel (figure 7, figure 8).

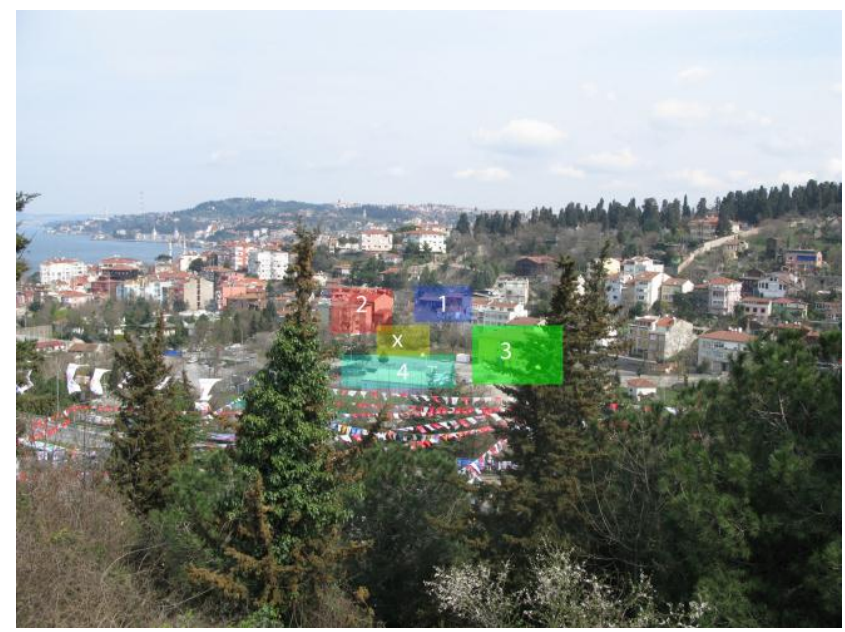

Figure 7. The location of the actual buildings

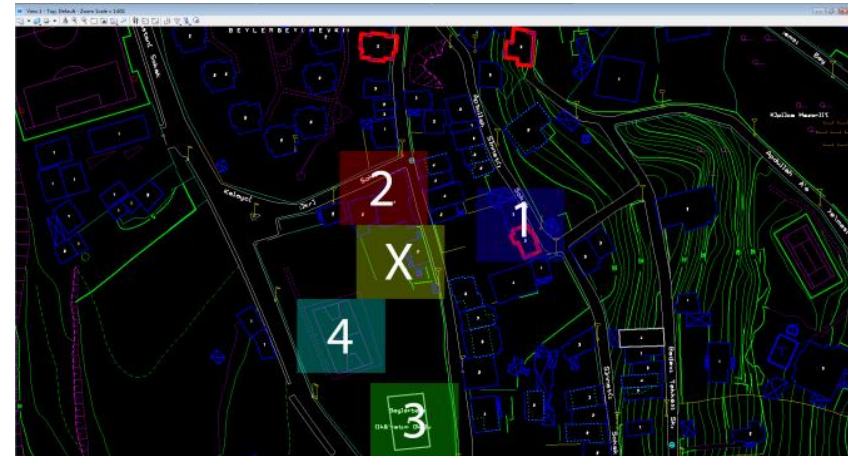

Figure 8 . The location of the actual buildings

\subsection{Determination of the Building by Using Historical Terrestrial Photograph and Terrestrial Aligned Google Earth Cropped Image}

Web-based services such as Google Earth and Google Maps have popularized access to geospatial data, and today citizens routinely rely on such services, and the specialized services that leverage them, for driving directions, buying houses, and planning foreign travel.

(http://googleblog.blogspot.com/2011/10/google-earthdownloaded-more-than-one.html\#!/2011/10/google-earthdownloaded-more-than-one.html, 16 April 2012)

Google Earth is available in 13 languages and has been downloaded over 350 million times by people from around the world in 2008. (bbbb) As of October 2011 Google Earth has been downloaded more than a billion times.

(http://www.axetue.com/2011/10/12/google-earth-billiondownloads/, 16 April 2012)

Google Earth uses a wide range of high resolution image including, aerial photos, IKONOS and Quickbird.
(http://en.wikipedia.org/wiki/Google_Earth\#Imagery_and_coor dination, 16 April 2012)

SketchUp is a 3D modeling program marketed by Google and designed for architectural, civil, and mechanical engineers as well as filmmakers, game developers, and related professions. (http://en.wikipedia.org/wiki/SketchUp, 16 April 2012)

The program, which is designed for ease of use, (http://sketchup.google.com/product/features.html, 16 April 2012) allows placement of models within Google Earth.

Microstation is a graphical data editor, which is used for creation and modification of drawings, plans, etc. This system has a large palette of PC graphic methods in a plane (2D) but also in a space (3D) (Samuhelová, 2004).

In order to find the location of the historical building the following operations were done sequentially.

- Six buildings in the historical photograph, which are survived, were identified (Figure 9).

- These six buildings were modelled with Google SketchUp software one by one by using the information which was taken from digital photogrammetric maps.

- The modelled buildings were placed in the Google Earth image.

- The approximate capture point of the historical photograph was determined by using Google Earth (Figure 10).

- The perspective of the Google Earth image was transformed into the same perspective of the historical photograph by several empirical trials and captured.

- The historical photograph was geometrically corrected by using captured Google Earth image as a reference coordinate system. Projective transformation was applied for geometric correction.

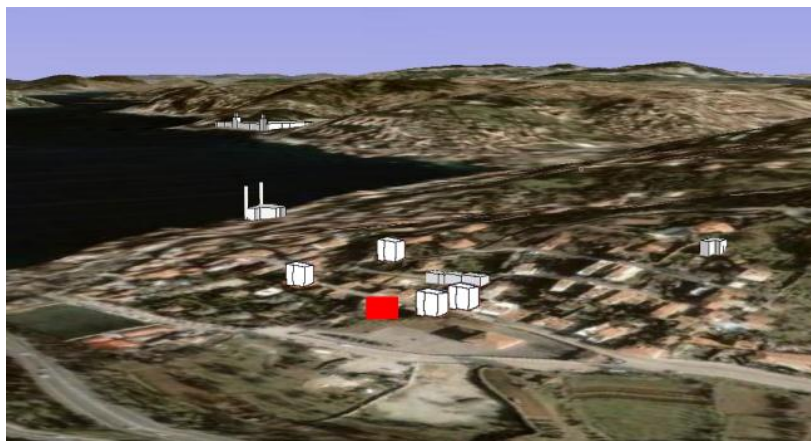

Figure 9. Control Point witch made with Google SketchUp

In the third method, the standard error of the transformation was greater than one pixel because of the same reasons which has been mentioned in second method. 


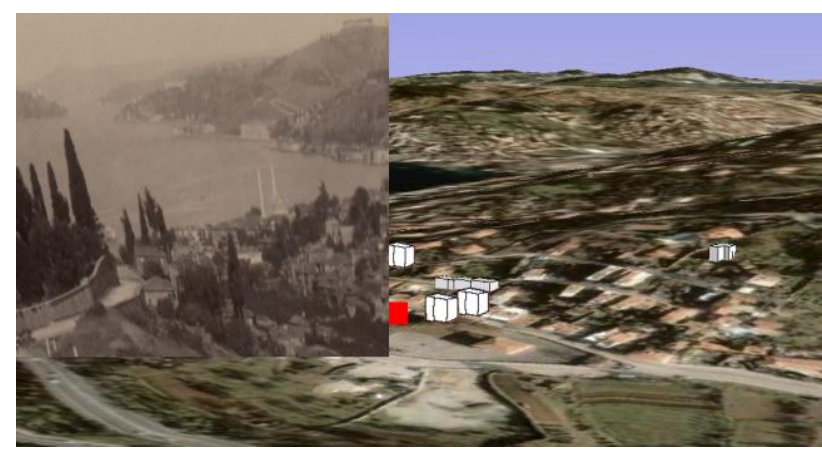

Figure 10. The location of the actual buildings

\section{RUSULTS}

Istanbul has many historical buildings. Some of them are exist today but very few of them have not survived. Usually these buildings are private and their owners want to redintegrate them. Due to nonexistence of these buildings the owners have to determine the location of the historical buildings for having governmental permission. For this purpose, photogrammetry is very useful, reliable method.

In the presented study, three different methods were applied to determine the localization of nonexistence historical building. Although these three methods were applied for the subject of the study, these methods can be used also for similar applications.

The main difficulty of the solved problem is unknown scale of photographs. Google Earth provides a good possibility to monitor the Earth in 3D, and to create different viewing perspectives. This feature of Google Earth was also used in the 3th method to determine the viewpoint of historical photograph.

The spatial errors for the determining the building locations are, 1.87 m., 3.89 pixels and 2.65 pixels for $1^{\text {st }}, 2$ nd and $3^{\text {rd }}$ methods respectively.

\section{REFERENCES}

Aldridge, D., 1989. How the Ship of Interpretation was Blown Off Course in the Tempest: Some Philosophical Thoughts. Heritage Interpretation, Vol. 1, The Natural and Build Environment, pp. 64-87

Aydar U.,Avsar E., Altan O., Obtaınıng Façade Plan Of A Historical Building With Orthorectification Of Single Images Gathered By Mobile Phone And Digital Camera, XXI International CIPA Symposium, Athens, Greece, 2007,

Balodimos, D., Lavvas, G., Georgopoulos, A. New Perspectives to Save Cultural Heritage. Wholly Documentation Holly Monuments, Proceedings of the CIPA 2003 International Symposium:", pp. 502-506, Turkey, 2003.

G.Pop, 2008. Integrating Photogrametric Technologies and Geodetic Methods for 3D Modeling, The International Archives of the Photogrammetry, Remote Sensing and Spatial Information Sciences. Vol. XXXVII. Part B5. Beijing 2008, pp.549-554

Hewison, R. 1989. Heritage: An Interpretation. Heritage Interpretation, Volume 1, The Natural and Build Environment, pp. 15-23

Kirchhoefer, Chandler M. K., Wackrow J.H., Rene, 2011, Cultural heritage recording utilising low-cost close-range photogrammetry, Proceedings of CIPA 23rd International Symposium, 12 - 16 September 2011, Prague, Czech Republic.

Samuhelová A, 2004, Using terrestrial photogrammetry for Documentation of sights, Aplikácia Pozemnej Fotogrametrie Pri Dokumentácii.

Shashi M., Jain K, 2007, Use of amateur cameras in architectural photogrammetry, Map World Forum Hyderabad, India, pp. 247667.

Stojaković V., 2008, Terrestrial Photogrammetry And Application To Modeling Architectural Objects, Architecture and Civil Engineering Vol. 6, No 1, , pp. $113-125$.

Uzzell, D.L. 1989. Introduction: The Natural and Built Environment. Heritage Interpretation, Vol. 1, The Natural and Built Environment, pp. 1-14

Yilmaz, H.M., Yakar, M., Gulec, S.A., Dulgerler, O.N. 2007. Importance of digital close-range photogrammetry in documentation of cultural heritage. Journal of Cultural Heritage. 8(4), pp. 428-433

Tsioukas V., 2007, Simple Tools For Architectural Photogrammetry, XXI International CIPA Symposium, 01-06 October, Athens, Greece,

Wei L., Xiao J., 2012, Factors Affecting The Take-Off Of Innovative Technologies: Evidence From Digital Cameras, Applied Economics, Volume 44, Issue 32, pp. 4143-4152 